\title{
ASPECTS OF CROSS-BORDER MOBILITY IN THE CONTEXT OF HEALTH TOURISM
}

\author{
Vasyuta Evgeniya Aleksandrovna \\ Ushakov Denis Sergeevich
}

\begin{abstract}
South-Russian Institute of Management, Russian Presidential Academy of National Economy and Public Administration under the President of the Russian Federation, Rostov-on-Don, Russia
\end{abstract}

International migration of medical personnel inevitably results in a shortage of personnel in the healthcare sector in those countries from which healthcare professionals migrate. This is generally because they strive for higher wages, favorable working conditions, educational opportunities, new professional experience, and career growth. Such movements involve crossing the borders of the states. These processes result in a change in the quantitative and qualitative composition of medical personnel in both "donor" and "recipient" countries, affecting the professional structure of personnel, demographic profile, and geographical allocation. Such socioeconomic changes certainly affect the effectiveness of healthcare systems and medical care in various regions. This article presents an overview of international migration of medical personnel from the analytical point of view, analyzing its underlying causes, revealing the relationship in the movement of patients and healthcare workers in the context of health tourism, and suggesting mechanisms for regulating the migration of medical personnel.

Keywords: international migration; shortage of medical personnel; healthcare; medical tourism; demand for medical and health services; international cooperation.

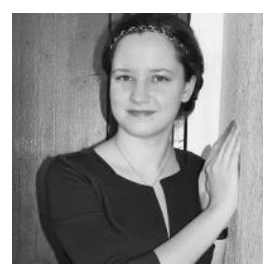

Vasyuta Evgeniya Aleksandrovna

MBA (International economy), Senior Lecturer, State and Municipal Administration Department, SouthRussian Institute of Management of the Russian Presidential Academy of National Economy and Public Administration under the President of the Russian Federation, Rostov-on-Don, Russia

Research interests: global services market, international tourism, health tourism, tourism macromarketing

e-mail: eug.vasuta2012@yandex.ru

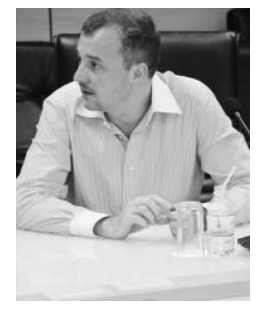

Ushakov Denis Sergeevich

Doctor of economics, Professor

Department of International Economic Relations, South-Russian Institute of Management -Russian Presidential Academy of National Economy and Public Administration under the President of the Russian Federation, Rostov-on-Don, Russia

Research interests: service markets globalization, tourism MNC, international regulation of tourism markets 
Rapid increase in the number of migrants in the international scene is one of the factors affecting societies at the current stage of development. This process is followed by evident intensification of cross-border movements of both patients and medical personnel (not only of the top-level but also of the mid-level), which in turn affects the healthcare sector on both sides of this movement. It is important to note that this process is associated with the growing practice of hiring foreign medical workers, and with rapid development and distribution of medical tourism globally.

Thus, structural changes at the market of medical and therapeutic-sanitary work are happening mainly due to the growing international mobility of not only medical personnel but also other categories of population, including patients.

To confirm the relevance of this research topic, it is important to answer several critical questions, namely:

- Does the growth of cross-border mobility provide new opportunities for medical personnel and patients?

- Do such movements entail socioeconomic problems?

Over the past decade, the problem of medical staff shortage has become one of the most acute problems the global community is facing. This fact is confirmed by the data presented in the report of the World Health Organization (WHO) "A Universal Truth: No health without workforce". According to the report, there is a shortage of approximately 7 mln of medical personnel, and according to the forecasts, by 2035 this figure will increase to 13 mln (Berezovaya, 2017).

Tab. 1 presents the analysis of medical personnel availability in the WHO regions.

Table 1. Medical personnel availability in the WHO regions, 2017-2018

(Source: Vlasova, 2019)

\begin{tabular}{|c|c|c|}
\hline Region & $\begin{array}{c}\text { Top-level medical } \\
\text { personnel }\end{array}$ & $\begin{array}{c}\text { Mid-level medical } \\
\text { personnel }\end{array}$ \\
\hline African & 2.7 & 11.2 \\
\hline American & 21.3 & 73.1 \\
\hline South-East Asia & 7.8 & 13.4 \\
\hline European & 36.6 & 90.7 \\
\hline Pacific & 26 & 36.3 \\
\hline
\end{tabular}

As we can see in Tab. 1, European region is the most supplied with medical personnel, while African region is the least provided of all. For example, in the United Republic of Tanzania, there are only 0.1 doctors per 10,000 people. In general, there are approximately 14 doctors and 29 middle-level medical personnel per 10,000 people on the planet (Voskresenskii, 2015).

According to the WHO experts, to ensure optimal medical care, there should be 23 health care professionals per 10,000 people.

In case of Russia, for example, shortage of healthcare personnel is most acute in the northern regions of the country. According to the Rosstat data, by the end of 2018, domestic medical institutions were in need of personnel (except for dentists only). The need for replacement of certain vacancies accounted for approximately $12 \%$ in the total number of jobs. Most medical institutions needed anesthesiologists, resuscitation specialists, narcologists, pediatricians, and neonatologists. 


\section{ASPECTS OF CROSS-BORDER MOBILITY IN}

Even in the capital, Moscow City, staffing of medical institutions with top-level medical personnel accounts for about $89 \%$, middle-level staff $-88 \%$.

The abovementioned WHO report also defined the primary causes for staff shortage in the healthcare sector:

- $\quad$ aging of medical personnel and, consequently, gradual retirement;

- $\quad$ switching workplaces and even professions as such due to wage differences;

- low prestige of the medical profession and, consequently, insufficient number of young people who would want to master this profession;

- population growth and consequent increase in the number of diseases with a deficit of doctors needed for their treatment.

Therefore, several factors (including political, socioeconomic, demographic and technological ones) contribute to the growing need for highly qualified medical personnel. Moreover, besides the growing need for medical personnel, the diversity of doctors' profiles needs to be increasing. This is primarily because of rapid changes in the epidemic situations across the globe, changes in the structure and nature of morbidity associated with the spread of non-communicable chronic diseases, emergencies, and natural disasters that require prompt and professional medical response.

According to the World Bank forecasts, there should be approximately $42 \mathrm{mln}$ new positions in the field of healthcare and social services across the globe by 2030 (Koblev, 2016).

Therefore, it is important not only to train new healthcare professionals but also to cover the territories, which are currently lacking medical personnel.

The World Bank experts have determined and modeled the cumulative needs associated with the need for healthcare workers by 2030 in different regions across the world. This forecast was based on the dynamics of macroeconomic indicators for 170 countries (see Tab. 2) (Koroleva, 2015):

- the demand for labor and its movement;

- the level of GDP per capita;

- the level of public health expenditures;

- population over 65 years old.

Table 2 - Projected demand for healthcare tourism in 2030

(Source: Koroleva, 2015)

\begin{tabular}{|l|c|}
\hline \multicolumn{1}{|c|}{ WHO region } & $\begin{array}{c}\text { Projected demand for 2030, mln } \\
\text { people }\end{array}$ \\
\hline Africa & 3.6 \\
\hline American countries & 14.1 \\
\hline Eastern Mediterranean & 7.3 \\
\hline Europe & 20.1 \\
\hline Southeast Asia & 9.3 \\
\hline Western Pacific & 21.6 \\
\hline World (in total) & $\mathbf{7 6}$ \\
\hline
\end{tabular}


One cannot ignore the fact that the movement of medical personnel associated with the solution of personnel own problems is a long-standing and rather popular practice, and not only at the national levels but also on the global scale.

In the 1950s, migration of doctors was observed primarily inside European region. However, since the middle of the 1970s more than half of this migratory flow originated from Asian countries, primarily from China and India (Pirogov, 2015).

Today, composition of the top-20 list of the major donor countries in relation to medical personnel (done only for the OECD) is much more heterogeneous but it still includes some European countries. See Fig. 1 for more details.

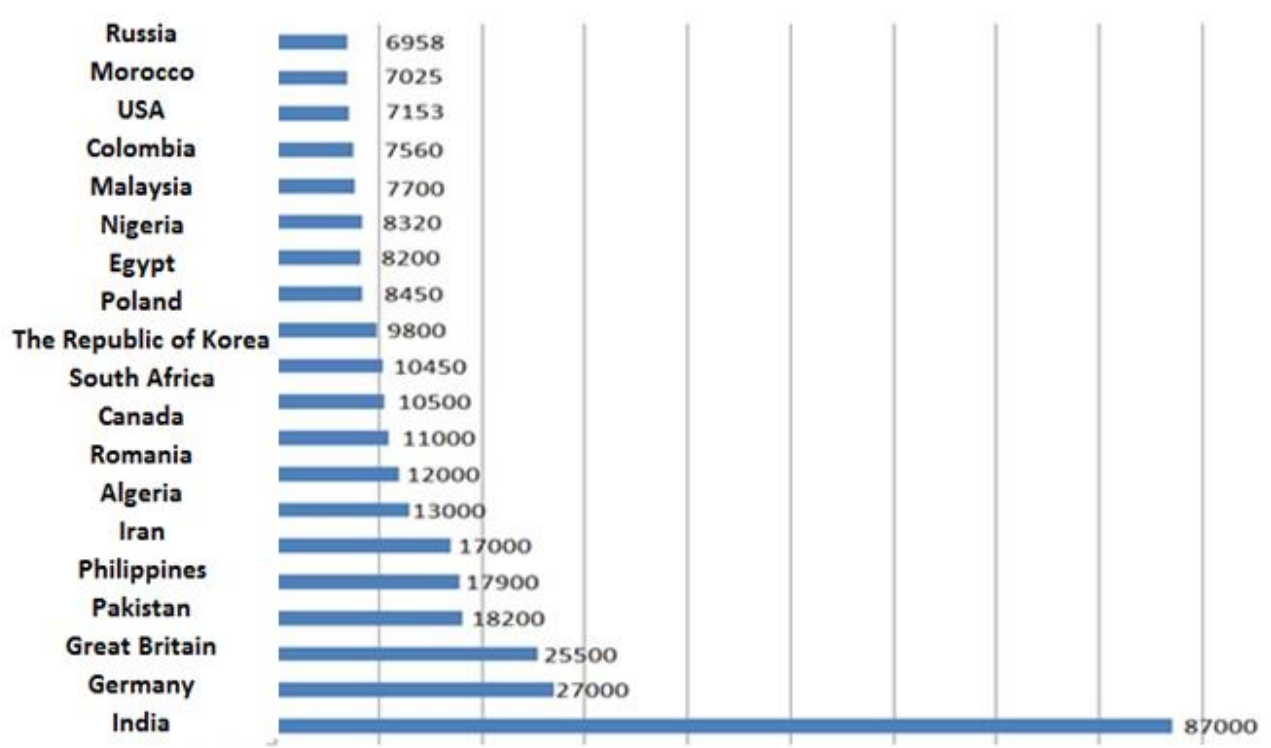

Figure 1 - Major donor countries in relation to medical personnel, among the OECD countries, 2017-2018, people

(Source: Trushkina, 2015)

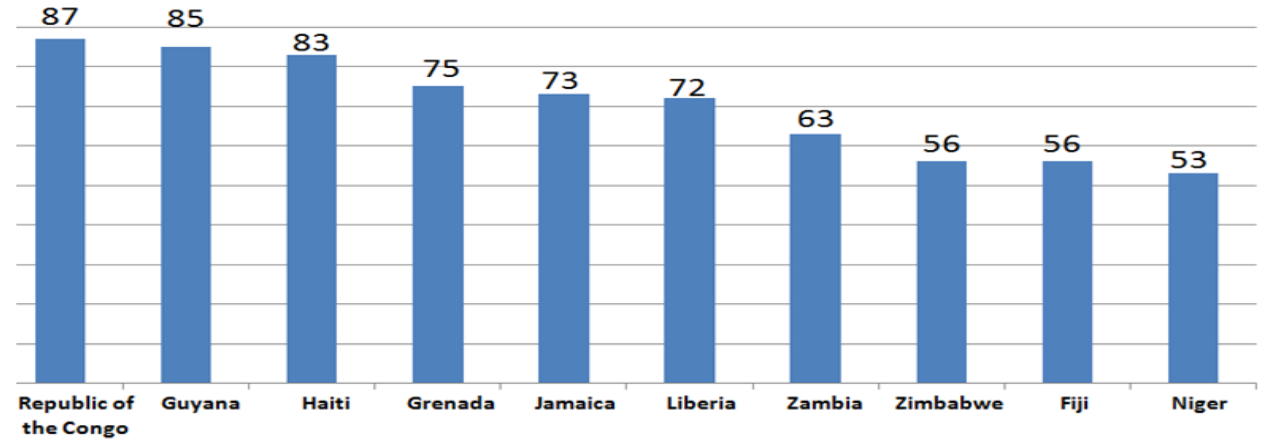

Figure 2 - Countries with the highest emigration rates among doctors, 2017-2018, in \% (Source: OECD 2017 data)

In this group of countries, healthcare professionals have mostly low or medium incomes. Moreover, they are forced to engage in extra employment processes, often for the sake of professional self-actualization mostly, not due to financial motivation. 


\section{ASPECTS OF CROSS-BORDER MOBILITY IN}

Thus, the first decade of the 21 st century showed an increase in the number of foreign medical personnel, of both top and mid level (see Fig. 3) (Traskevich, 2016).

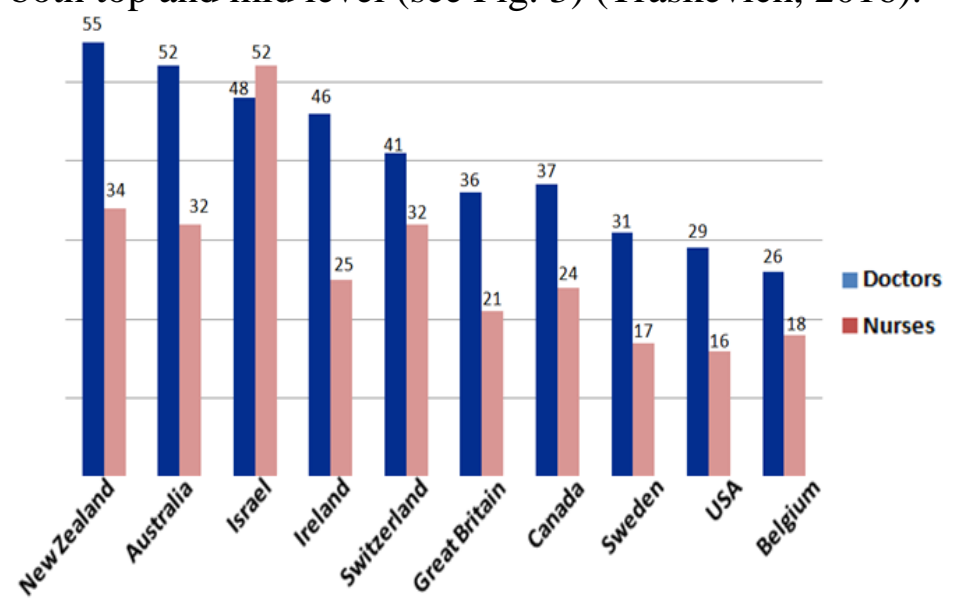

Figure 3 - Comparative analysis of the share of foreign medical personnel by the country of residence

(Source: OECD, 2017)

Outlining the opportunities received by medical personnel due to migration, it is important to mention the factors that determine and support migration inflows:

- common language;

- similar sociocultural environment;

- mutual recognition and common qualifications;

- geographical proximity which is contributing to the ease of movement;

- the already existing migrant professional community.

Next, it is advisable to define the so-called poles of attraction and repulsion for migration and international hiring of healthcare workers.

Motives forcing people to migrate can be different, and types of migration among healthcare workers may vary among different countries and at different times.

Migration can be not only one-way, from a country of origin to a country of destination. Healthcare workers can leave one country to work in another and then return to their home country or move to a third one. They can even live in one country and regularly cross the national border to work in another.

Better travel conditions and improved communications, coupled with employment opportunities, can facilitate this circulation of workers.

Worldwide practice recognizes that international migration of medical personnel has a significant impact on the development of health tourism. Today healthcare tourists, who are primarily patients, do not only perform medical and recreational trips, but require full medical care, including complex medical examination and sometimes serious surgical operations.

In this case, medical institutions in different countries require personnel with the knowledge of various medical systems and peculiarities of other national healthcare systems.

National governments also carry out extensive work in terms of health tourism.

Thus, South Korea stands ready to prevent risks associated with the provision of emergency medical care to foreign nationals, while in Turkey the national government subsidizes the healthcare provided to foreign tourists (Statistics by Penang Monthly, 2017). 
Today, tourists are striving for high-tech medical care, which is prescribed clinically. As a rule, tour operators, who provide consultations on commercial recreational tours, organize this process as well.

Last but not least, it is the medical migrants who strive to reduce the possible medical risks to a minimum, trying to provide patients with the full range of medical services related specifically to the diagnosis and treatment of serious diseases.

Going back to the question raised earlier, it can be said that migration of medical personnel certainly has some positive effects.

First, this process smooths the imbalances observed at the healthcare labor market. Thus, $1 / 4$ of doctors surveyed in the UK in 2018, including $20 \%$ of Indian natives, could not find a relevant job in their home country before emigration.

Secondly, donor countries thus receive additional financial resources from other countries on a regular basis. In 2018, more than half of foreign doctors working in the UK sent about $25 \%$ of their earnings to their home countries.

Third, when doctors return to their home countries, they bring new technologies, new knowledge, and advanced skills, thus spreading technological innovations and new social norms onto their professional field.

In general, migrants traditionally occupy an ambivalent position in economic relations. In recipient societies, including their healthcare sectors, they are both producers and consumers of goods and services, whilst in donor societies they generate reciprocal movement of resources.

Population movements in general, including healthcare tourism, provide a mechanism for spatial reallocation of healthcare needs: on the one hand, they reduce or postpone their manifestation in the countries of origin and on the other - increase and modify their structure in the countries of destination.

However, relocations of medical professionals also affect the satisfaction of these needs, limiting it in donor countries, and expanding and diversifying the supply of medical services in recipient countries.

In conclusion, it is useful to characterize the mechanism that can streamline the migration process of healthcare workers.

\begin{tabular}{|c|c|}
\hline Factors & Characteristics \\
\hline $\begin{array}{c}\text { Strengthening bilateral ties between } \\
\text { the country of origin and the country } \\
\text { of destination }\end{array}$ & $\begin{array}{l}\text { Exchange of personnel, skilled support staff and } \\
\text { channeling of resources to the countries of origin }\end{array}$ \\
\hline Exchange of experience & $\begin{array}{c}\text { Relocation of personnel to other medical } \\
\text { institutions for gaining new experience and } \\
\text { organizational development and, consequently, } \\
\text { career growth }\end{array}$ \\
\hline $\begin{array}{l}\text { Educational support for medical } \\
\text { personnel }\end{array}$ & $\begin{array}{c}\text { Coverage of costs associated with obtaining } \\
\text { additional professional education (for a certain } \\
\text { fixed period of time), aimed at improving } \\
\text { personnel skills before returning to the country of } \\
\text { origin }\end{array}$ \\
\hline $\begin{array}{c}\text { Accelerating paperwork for healthcare } \\
\text { professionals (at the state level) }\end{array}$ & $\begin{array}{c}\text { Processing of papers on preferential terms for } \\
\text { foreign professionals }\end{array}$ \\
\hline
\end{tabular}




\section{ASPECTS OF CROSS-BORDER MOBILITY IN}

Thus, migration of top- and mid-level health workers continues to be global. However, outflow of medical personnel from developing countries exacerbates the development of personnel problems, worsening the level of public healthcare and availability of medical care as such, thus creating threats to national healthcare. Although it is impossible to stop the leakage of medical personnel under the conditions of socioeconomic backwardness, rich countries can soften the severity of this problem by compensating the losses to poor countries, promoting their healthcare and making migration of health personnel at least circular.

\section{References:}

Berezovaya, L.G. (2017). The history of tourism and hospitality: a textbook for bachelors. Moscow: Urait Publishing House.

Vlasova N.Y. (2015). Stages of establishing the world market of medical services. Upravlenets, 7-8.

Voskresenskii, V.Y. (2015). International tourism: a textbook for university students studying "Socio-cultural service and tourism". Moscow: UNITY-DANA.

Koblev, R.M. (2016). Topical issues of the post-crisis economy. Sochi: Academy of Advanced Training for Managers and Specialists of the Spa Business, Sport and Tourism.

Koroleva, L.V. (2015). Tourism geography. Moscow: Russian International Academy of Tourism, Logos.

Pirogov, M.V. (2015). Prerequisites and conditions for the formation of the world market of medical services. Economist of a Medical Institution, 4.

Trushkina, L.Y. (2015). Economics and Health Management. Rostov-on-Don.

Health at a Glance (2017). OECD Indicators, OECD Publishing. Retrieved from: http://dx.doi.org/10.1787/health_glance-2017-en

Traskevich, N. (2016). New Challenges and Boundaries in Tourism: Policies, Innovations and strategies: Proceedings of the International Conference on Tourism (ICOT 2016). Naples.

Statistics by Penang Monthly. Retrieved from: http://penangmonthly.com/medical-tourism-a-billionringgit-industry-for-penang/\#ftn1b

Paper submitted

Paper accepted for publishing

Paper published online
26 May 2019

28 July 2019

01 October 2019 